\title{
Analysis of FUNAI's Integrated Fire Management activities from the perspective of the Illicit Acts Prevention Coordination
}

Isolde Lando*, Clara Ferrari e Guilherme Franco

Indian National Foundation - FUNAI, Brasília, Brazil

*contact email: isolde. lando@funai.gov.br

\begin{abstract}
This study aims to analyze the activities related to forest fire prevention and support carried out by the Indian National Foundation - FUNAI between 2015 and 2018 within the scope of Programs developed by the Illicit Acts Prevention Coordination - COPI of the Territorial Protection Directorate - DPT of FUNAI (eg Fire Prevention Group - GPI), as well as the Technical Cooperation Agreement - ACT Prevfogo / Ibama and FUNAI. In this context, we will analyze what the public policy of the Integrated Fire Management - MIF was like before and after the partnership between Prevfogo / Ibama and FUNAI, and how the ACT has contributed to modify the vision about the MIF and the traditional usage of fire, both "in" and "out" FUNAI. "In" FUNAI, through a new institutional look at fire which was previously seen only from the socio-cultural aspect of Indigenous communities and not as an important element in forest fire prevention actions, with annual activities of MIF in Indigenous Lands, or as an element of territorial protection, as the Indigenous Federal Brigades - BRIFs constantly act within the territories. And "out " of FUNAI (institutions and society) under the possibility of a new look at the traditional use of fire by Indigenous communities that had been previously seen by institutions and society only in the negative aspect and not as an activity to prevent large forest fires. The ACT allowed FUNAI to expose to external actors (institutions and society) the importance of traditional fire usage for Indigenous communities as a sociocultural instrument. This usage was until then fought and was not integrated into Public Policy. Therefore, we consider the partnership provided by the ACT positive, both to modify the intra-institutional and interinstitutional views on the MIF, and to deconstruct the prejudice of institutions and society against traditional fire usage by Indigenous communities by rescuing this usage among the communities and especially by inserting the vision of Indigenous communities in the Federal Government's MIF public policies.
\end{abstract}

Keywords: Traditional Usage of Fire, Technical Cooperation Agreement, Indigenous Communities, Public Policies. 